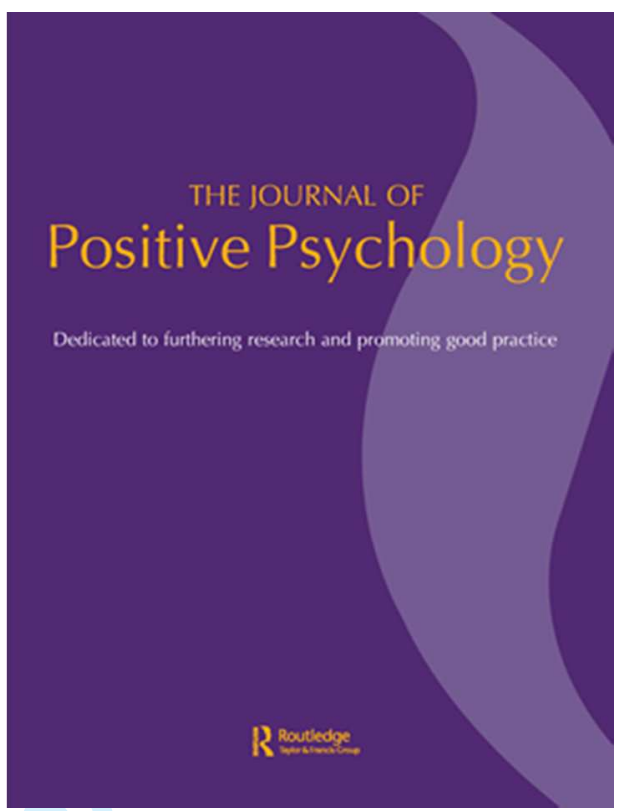

\title{
Happy-Productive Groups: How Positive Affect links to Performance through Social Resources
}

\begin{tabular}{|r|l|}
\hline Journal: & The Journal of Positive Psychology \\
\hline Manuscript ID & RPOS-2017-0148.R2 \\
\hline Manuscript Type: & Original Paper \\
\hline Date Submitted by the Author: & n/a \\
\hline Complete List of Authors: & $\begin{array}{l}\text { Peñalver, Jonathan; Universitat Jaume I } \\
\text { Salanova, Marisa; Universitat Jaume I } \\
\text { Martínez, Isabel; Universitat Jaume I } \\
\text { Schaufeli, Wilmar; Utrecht University; KU Leuven }\end{array}$ \\
\hline Keywords: & positive affect, broaden-and-build, creativity \\
\hline Keywords (author supplied): & $\begin{array}{l}\text { Group Positive Affect, Group Social Resources, Group Performance, Happy- } \\
\text { productive groups, In-Extra Role Performance }\end{array}$ \\
\hline & \multicolumn{2}{|l}{} \\
\hline
\end{tabular}


HOW POSITIVE AFFECT LINKS TO PERFORMANCE

Running Head: HOW POSITIVE AFFECT LINKS TO PERFORMANCE

Happy-Productive Groups: How Positive Affect links to Performance through Social Resources

Jonathan Peñalver*, Marisa Salanova*, Isabel M. Martínez* and Wilmar B. Schaufeli** *WANT Research Team, Universitat Jaume I, Spain ** KU Leuven \& Utrecht University

Correspondence concerning this paper should be addressed to: Jonathan Peñalver. Department of Social Psychology. Universitat Jaume I. Avenida Sos Baynat, s/n. 12071. Castellón de la Plana (Spain). Phone: +34 964 729580. E-mail: jpenalve@uji.es.

Marisa Salanova. Department of Social Psychology. Universitat Jaume I. Avenida Sos Baynat, s/n. 12071. Castellón de la Plana (Spain). Phone: +34 964 729583. E-mail: salanova@uji.es

Isabel M. Martinez. Department of Social Psychology. Universitat Jaume I. Avenida Sos Baynat, s/n. 12071. Castellón de la Plana (Spain). Phone: +34 964 729585. E-mail: $\underline{\text { imartine@ uji.es }}$

Wilmar Schaufeli. Department of Psychology. Utrecht University. Phone: +31(30)253 3460. \& Department of Psychology, KU Leuven. Phone +32 163792 39: E-mail: $\underline{\text { w.schaufeli@uu.nl }}$ 


\begin{abstract}
The current study extends the Broaden \& Build Theory to the collective (i.e., groups) level of analysis, focusing on the mediating role of group social resources (i.e., cohesion, coordination, teamwork, supportive team climate) between group positive affect (i.e., enthusiasm, optimism, satisfaction, comfort) and group performance (i.e., inand extra- role performance, creative performance). To test our hypotheses, we conducted two studies using independent samples. Study 1 is a laboratory study with 449 participants nested in 112 small groups who performed an organizational simulation creative task. Study 2 is a field study that aggregated scores of 2,159 employees nested in 417 groups. In both the lab and field studies, structural equation modelling results revealed that group social resources fully mediate the relationship between group positive emotions and performance.
\end{abstract}

Keywords: Group Positive Affect, Group Social Resources, Group Performance, Happy-productive groups, In- and Extra- Role Performance, Creative Performance, Broaden \& Build Theory. 
Happy-Productive Groups:

How Positive Affect is linked to Performance through Social Resources

\section{Introduction}

Affect is the core of human beings' psychological life, and research on affect is extensive because it influences a variety of cognitive, social, and biological processes (Lewis, Haviland-Jones, \& Barrett, 2010). Affect has been defined as an umbrella term for an extensive array of emotional experiences, including emotions and mood (Fernández-Abascal, 2009). In recent years, researchers and practitioners have begun to focus on positive aspects of individuals, such as positive affect, giving rise to the socalled "affective revolution" (Barsade, \& Gibson, 2007).

In the organizational context, scholars have extensively reviewed the happyproductive worker thesis; that is, "happy" individual workers will perform better than "unhappy" ones (Wright, \& Cropanzano 2007). However, numerous studies show that happiness (i.e., positive affect) not only occurs at the individual level, but also at the group level, through several mechanisms (e.g., emotional contagion) (Barsade et al., 2007; Kelly \& Barsade, 2001). In spite of the importance of groups in organizations, research on the relationship between happy groups and productive groups, i.e. happyproductive group, is not abundant. Specifically, Kelly and Spoor (2013) determined that the number of studies that openly pay attention to the effect of positive affect on group performance is limited, and even fewer studies have examined the psychosocial mechanisms that could explain this relationship. Why do groups perform better when they are feeling good? In this regard, Rhee (2007) established that when group members interact together, they build social resources understood as those aspects of group functioning that emerge from interpersonal dynamics among members, which can be 
functional in achieving good performance (Oh, Chung, \& Labianca, 2004). This group social resources are a key mechanism that explains the relationship between group positive emotions and group outcomes (Rhee, 2007).

The aim of this study is to explore how group positive affect leads to group performance by building group social resources through social interactions among group members. Therefore, it is important to examine whether the relationship between group positive affect and group social resources is associated with group performance, such as in- and extra- role performance.

In the present study, we attempt to make four theoretical contributions to the literature. First, according to the Broaden and Build Theory (B\&B), positive emotions broaden people's momentary thought-action repertoires, build their personal resources, and enhance their health and fulfilment (Fredrickson, 1998, 2001). We intend to expand Fredrickson's (2001) B\&B theory by taking teamwork, coordination, cohesion, and supportive team climate into account as specific social resources that could be built through positive affect at the collective level (i.e., group). Second, following Rhee's proposal (2007), we intend to examine different group social resources as a mediator between group positive affect and group performance. In order to test mediation, we suggest different group positive emotions (i.e., enthusiasm, optimism, satisfaction, comfort), different group social resources (i.e., teamwork, coordination, cohesion, and supportive team climate), and different types of group performance (in- and extra-role performance, creative performance). Third, although group positive affect has been studied (Rhee \& Yoon, 2011; Barsade \& Knight, 2015), a review of the literature showed that the term happy-productive group has not been analyzed. Therefore, we intend to add to the research on the happy-productive group, by explicitly addressing the difference between a happy group and a productive group. Finally, Gable and 
Harmon-Jones (2008) determined that positive emotions and positive mood have similar effects on cognition and behavior. To support this conclusion and extend it to the group level of analysis, we tested positive emotions and positive mood to obtain a comprehensive picture of group positive affect.

In addition to the theoretical contribution, the current study also makes two methodological contributions. First, we used aggregated scores for a group-level analysis (cd. Referent-Shift Consensus model; Chan, 1998) because our interest was to study group positive affect. Second, we tested the ecological validity of the results by using two independent studies with different samples (i.e., university students, employees) and methods (i.e., laboratory study, field study).

Finally, another strength of this study is the fact that we included the leaders/supervisors' ratings as measures of in- and extra-role performance, and more objective evaluator ratings as measures of creative performance, in order to obtain an external performance assessment and avoid common method variance.

\section{THEORETICAL BACKGROUND AND HYPOTHESES}

\section{The Broaden and Build theory of positive emotions}

According to the Circumplex model (Russell, 1980; Warr, 1990), the emotions are based on two core dimensions: pleasure and arousal. The horizontal dimension ranges from unpleasant to pleasant, whereas the vertical dimension ranges from low to high activation. Hence, positive emotions comprise high-activation pleasant emotions (e.g., enthusiastic, glad, happy, excitement, joy, contentment, cheerful, optimistic) and low-activation pleasant emotions (e.g., comfortable, drowsy, calm, relaxation, contentment). 
With substantial empirical evidence, the Broaden and Build theory of positive emotions by Fredrickson $(1998,2001)$ shows that, first, positive emotions (e.g., joy, contentment, interest) broaden people's momentary thought-action repertoires (e.g., flexibility, creativity) and, afterwards, build enduring personal resources (i.e., physical, social, psychological, intellectual). For instance, joy as a high-activation pleasant emotion motivates to play and explore the limits, which eventually leads to building social bonds and increasing levels of creativity (Fredrickson \& Cohn, 2008).

It is not surprising that Aristotle called humans the social animal because social relationships can help to undo some problems and improve wellbeing (Semmer \& Beehr, 2014). In particular, the effect of positive emotions extends into the social domain in terms of expanded social connections, social support, and high-quality friendship bonds (Fredrickson, 2013; Kok \& Fredrickson, 2010; Kok, et al., 2013; Vacharkulksemsuk \& Fredrickson, 2013). Again and again, the literature has shown that positive emotions provide benefits related to social processes such as prosocial behavior and sociability (Lyubomirsky, King, \& Diener, 2005), social connectedness (Mauss, et al., 2011), and social support (Salanova, Bakker, \& Llorens, 2006). In sum, the effect of positive emotions achieves several social benefits, and it is crucial to examine their interpersonal effects in order to fully understand the role of emotions (Van Kleef, Homan, \& Cheshin, 2012).

In groups, positive emotions strengthen an affiliation function (Van Der Schalk et al., 2011), enhancing bonds and social relationships (Spoor \& Kelly, 2004). Considering the importance of social aspects (i.e., social resources) at the individual level, we propose that they could be relevant at the group level as well (i.e., group social resources). Therefore, in the current study, we consider social resources in groups as 
effects of positive affect and also as a psychosocial mechanism to explain how shared positive affect in groups is related to better group performance.

\section{Group positive affect and Group social resources}

Positive affect not only involves internal states that occur at the intra-individual level, but also processes developed between individuals, that is, at the group level (Barsade et al., 2007; Kelly et al., 2001). Considering that groups, not individuals, often take decisions and solve problems (Cohen \& Bailey, 1997; Fisher \& Ashkanasy, 2000), it is important to study how positive affect drives the behaviors and outcomes of groups (Barsade et al., 2007). Group positive affect based on affective convergence is defined as the affective composition of the group members (Barsade \& Gibson, 1998), resulting from feeling similar levels of individual emotions when people work together (Barsade et al., 2015).

Recent research has confirmed the influence of group positive affect on group behaviors (Mackie, Smith \& Ray, 2008), group functioning (Barsade \& Gibson, 2012), and appropriately utilizing group resources (Meneghel, Salanova \& Martínez, 2014; Spoor \& Kelly, 2006). Resources are defined as "those physical, psychological, social, or organizational aspects of the job that may be functional in achieving work goals" (Demerouti, Bakker, Nachreiner, \& Schaufeli, 2001, p. 501). The resources generated are lasting in time, causing permanent dynamic processes with an impact on health, personal growth, and success over time (Fredrickon \& Cohn, 2008). Specifically at the group level, social resources (i.e., social capital) refer to those aspects of group functioning that emerge from interpersonal dynamics among members. It is important to highlight that groups with high social resources can more successfully manage other types of group resources (i.e., competence, organizational) (Oh, et al., 2004). 
The present study focuses on four specific group social resources that have been shown to be associated with group positive affect, namely, teamwork, coordination, cohesion, and supportive team climate. Teamwork can be described as the interactions among members of the group to achieve common and shared goals (Sánchez Pérez, 2006). Evidence shows that happiness as a positive affect with high activation/high pleasure, is associated with better teamwork (Diener, \& Oishi, 2005). Coordination refers to communication and activities related to time schedules (Stout, Salas, \& Carson, 1994; Wagner, 1995), and higher positive affect (e.g., excitement, , enthusiastic, calm, relaxation) has been related to better group coordination (Sy, Côté, \& Saavedra, 2005). Spoor and Kelly (2004) claimed that one role of group affect is to enable the development of group bonds, which may occur through cohesion. Cohesion is a multidimensional construct consisting of interpersonal attraction, commitment to task, and group pride that keeps members together (Mullen \& Copper, 1994). For example, Vacharkulksemsuk (August, 2013) conducted a study with 41 undergraduate teams, obtaining a positive relationship between group positive affect (e.g., joy, excitement, contentment, relaxation) and cohesion. Finally, a supportive team climate includes several facets such as participation, cooperation, and trust among members (Van Muijen, et al. 1999), in addition to support from the organization (González-Romá, \& Gamero, 2012). The latter study found that higher positive affect (i.e., cheerful, enthusiastic, optimistic) was associated with a higher support climate in teams (González-Romá, et al., 2012).

Subsequently, in the same way as in individuals (Fredrickson \& Losada, 2005), group positive emotions lead to building social resources that arise from interactions among members. In other words, when groups have high levels of positive affect, the group is more focused on achieving common goals, communication related to time 
schedules is better, the bonds among members are stronger, and the support climate is higher. This evidence allows us to take the B\&B theory a step further.

\section{Group social resources and group performance}

Grounded in a social functional perspective, Knight and Eisenkraft (2014) found that group social resources (i.e., aspects of the way members are related to others and to a group) have consistent positive effects on group performance. Social resources promote group performance because the members of socially integrated groups are coordinated and committed to group goals (Beal et al., 2003). Furthermore, we assumed that group social resources have a positive relationship with group performance because having a high level of social resources can benefit groups in terms of performance (Oh, et al., 2004; Van Emmerik \& Brenninkmeijier, 2009) and creative behaviors (Rodríguez-Sánchez, Devloo, Rico, Salanova, \& Anseel, 2016).

Performance is a construct that comprises two types of indicators, in-role and extra-role. According to Goodman and Svyantek (1999), in-role performance is related to the fulfillment of tasks that employees are expected to carry out as part of their job requirements. By contrast, extra-role performance refers to behaviors that are beneficial to the organization and go beyond job requirements. Recent research showed that groups with higher levels of cohesion, teamwork, and coordination have higher group performance (Meneghel, Martínez \& Salanova, 2016; Torrente, Salanova, Llorens \& Schaufeli, 2012; Vacharkulksemsuk, August, 2013). Specifically, extra-role behaviors include activities that enhance the exchange of information among colleagues, contribute in the improvement of interpersonal relationships, and generate an atmosphere of teamwork (O'Bannon and Pearce, 1999). Regarding the supportive team climate, climate influences performance because it encourages members to value their 
work, help other members, and satisfy social needs (Sun, Xu, \& Shang, 2012). Thus, group social resources imply a degree of interaction among participants, which has been found to be crucial for group success and better group performance (i.e., in-role, extrarole).

In addition, creativity at work can be defined as the production of useful, original ideas related to products, services, and processes (Amabile, 1997). Creative performance may contribute to organizational performance, help to solve problems, and create new products and services (Zhang \& Bartol, 2010; Gilson, \& Shalley, 2004).

According to the Componential Model of Creativity (CMC, Amabile, 1996; Amabile, \& Pratt, 2016) at individual/group level, creative performance requires the interaction of intrinsic motivation to do the task (e.g., positive affect such as interest, enjoyment and satisfaction), skills in the task domain (e.g. knowledge, expertise), and creativityrelevant processes (e.g., cognitive styles to taking new perspectives and thinking broadly), which operate in a similar manner as the Broaden process (Fredrickson, 1998, 2001). In addition, CMC proposes that the social environment influences creativity in multiple ways, such as interactions among group members and group dynamics. For instance, Hülsheger, Anderson, and Salgado (2009) established that cohesion is important for creative activities because it stimulates group members to interact with each other and facilitates the exchange of ideas within a supportive and non-threatening atmosphere. Different studies suggest that creativity increases in a group climate with an encouraging environment where people are collaborative, enthusiastic about new ideas, and non-critical (Amabile, 1998; Connolly, Jessup, \& Valacich, 1990). Regarding coordination, the literature shows diverse opinions about the effect of coordination on creative performance because the need to play with ideas under time limitations restricts idea generation and brainstorming (Gilson et al., 2004; Gilson, Mathieu, Shalley, \& 
Ruddy, 2005). However, rules and norms are important for group functioning (Taggar \& Elleis, 2007).

These considerations suggest that group social resources are needed to enable the effective functioning of creative performance because they lead members to create a perfect environment for developing creative ideas.

\section{The current study}

Positive emotions broaden people's momentary thought-action repertoires, building lasting social resources, and people who generate positive emotions are more likely to be social and friendly, which leads to developing a full and healthy life (Fredrickson et al., 2008). Analogous to the individual level, Rhee (2007) developed a theoretical framework that includes the antecedents, processes, and consequences of group positive affect. Feeling positive emotions (i.e., joy) broadens the interactions among group members through developing others' ideas and encouraging communication. These group momentary thought-action repertoires build enduring group social resources, such as friendship, a sense of membership, a feeling of closeness, social support, and social bonds. In the end, the development of group social resources enhances several group outcomes (e.g., creative performance) (Rhee, 2007). However, we attempted to improve these results by considering different group positive emotions (i.e., enthusiasm, optimism, satisfaction, and comfort), different group social resources (i.e., teamwork, coordination, cohesion, and supportive team climate), and different types of group performance (in- and extra-role performance, creative performance). In addition, Rhee (2006) only tested the model in a laboratory study, whereas we conducted two studies: laboratory and field. 
Consistent with the mediation proposed by Rhee's theory (2007), recent studies found that the relationship between group positive affect and several group outcomes is mediated by variables related to interactions among group members (Chi, Chung, \& Tsai, 2011; Baas, De Dreu \& Nijstad, 2008; Meneghel, Salanova \& Martínez, 2014, Shin, 2014). However, Kelly et al. (2013) determined that few studies openly address the effect of affect on group performance.

In the present study, we conducted two independent studies with different samples (i.e., university students, employees) and methods (i.e., laboratory study, field study). The first study is a laboratory study composed of a sample of university students, full time workers, and others types of workers. In order to test the ecological validity of the laboratory results, we proposed a second study, a field study composed of a sample of employees from different organizations.

In addition, previous reports about the effects of affect on broadening cognition and attention (Gable et al., 2008) determined that positive emotions and positive mood have similar effects on cognition and behavior, even though the conceptualizations of the emotional states (i.e., emotions, mood) are different. To support this conclusion and expand it to the group level of analysis, we evaluated group positive emotions (study 1) and group positive mood (study 2 ) to obtain a comprehensive view of the effect of people's positive affect on group behaviors.

Therefore, and taking the previous research into account, we formulated the following general study hypothesis (see figure 1): The relationship between group positive affect and group performance (i.e., in- and extra- role, creative performance) is fully mediated by group social resources. That is, group positive affect (i.e., enthusiasm, optimism, satisfaction, comfort) helps to build group social resources (i.e., teamwork, 
coordination, cohesion, supportive team climate), which in turn increase the performance (i.e., in- and extra- role, creative performance) of groups.

\title{
PLEASE INSERT FIGURE 1 ABOUT HERE
}

\section{STUDY 1}

The first study is a laboratory study with university students, full time workers, and others types of workers, such as the unemployed, retired people, and housewives. According to previous research on the Broaden and Build Theory, we expect group positive affect to be positively related to group social resources (Hypothesis 1). Furthermore, we expect group social resources to be positively associated with group performance (i.e., in-extra role performance, creative performance) (Hypotheses 2 and 3). Finally, we sought to uncover whether group social resources fully mediate the relationship between group positive affect and group performance (i.e., in-extra- role performance, creative performance) (Hypotheses 4 and 5). The model for Study 1 is displayed in Figure 2.

\section{PLEASE INSERT FIGURE 2 ABOUT HERE}

\begin{abstract}
Method
Sample and Procedure

The sample consists of 449 participants nested in 112 small groups. The small group size ranged from 2 to 5 members, and each group had a leader. The members of the sample were university students from different degrees (Psychology, Law, Engineering, etc.; $71.9 \%$ ), full time workers from a wide range of occupations (16.9\%), and others (e.g., unemployed, retired, housewives; $11.2 \%$ ). Specifically, $6.9 \%$ of these
\end{abstract}


university students had a job. In the entire sample, $64.4 \%$ of the participants were female, and the average age was 25.39 years $(S D=10.03)$. The leader sample was composed of university students from different degrees (35.7\%), full time workers from a wide range of occupations (37.5\%), and others (e.g., unemployed, retired, housewives; $26.8 \%$ ). Specifically, $15 \%$ of these university students had a job. In the leader sample, $50.9 \%$ of the leaders were female, and the average age was 36.27 years $(\mathrm{SD}=14.28)$. In order to collect the data, participants were recruited through a website, panels, and classes. The participants had to select a time and day of the week, and small groups were randomly formed depending on their choice, so the small groups had similar task skills. When each small group arrived at the laboratory, a leader was designated due to being older than the other participants in the group (a kind of status assignment similar to what occurs in companies). The leader's task was to control the time and manage the group. Then, researchers instructed to the group that they simulated to work for an organization dedicated to sell toys. During the session they had to complete a creativity task (i.e., design a poster that promoted a toy) in 45 minutes. Each participant received a small financial reward $(20 €)$ for taking part in the task and the high performance groups could receive an extra financial reward (until 450€). Researchers explained that the criteria to evaluate the performance were novelty, resolution and style. Finally, researchers provided the material to compose the poster. After this task, the leader and participants had to complete the questionnaire about the variables studied. In the end, external evaluators evaluated creativity.

\section{Measures}

Group Positive Affect. We measured four group affects (i.e., enthusiasm, optimism, satisfaction, comfort), representing how the group had felt during the task. These affects were chosen to represent the two dimensions proposed by the Circumplex 
Model (Russell, 1980; Warr, 1990). The respondent is asked to choose the position s/he thinks the group has on a Faces Scale (Kunin, 1955), between two bipolar adjectives (e.g., Unenthusiastic vs. Enthusiastic), with 7 faces ranging from 0 (frowning) to 6 (smiling). The alpha for the scale was .93. This scale was validated in Salanova, Llorens, Cifre, and Martínez (2012). In addition, the literature defines the emotions as an intense response produced by a particular cause and unfolding over short time spans (Frijda, 1986; Lazarus, 1991). Therefore, in study 1 we evaluated the positive emotions as the group's reaction when facing a stimulus (i.e. organizational simulation exercise about creative aspects).

Group Social Resources: We measured group social resources with 3 scales: Teamwork (3 items, i.e. "My team has set clear work objectives"; alpha =.71), Coordination (3 items, i.e. "My team was able to efficiently manage unexpected situations"; alpha = .88), and Cohesion (3 items, i.e. "The task has been realized in an amicable and pleasant atmosphere"; alpha =.94). Items were scored on a 7-point Likert scale ranging from 0 (never) to 6 (always). The Teamwork and Coordination scales were taken from the study by Salanova, Cifre, Llorens, Martínez and Lorente (2011), whereas the Cohesion scale was adapted from the study by Price and Mueller (1986). The Teamwork and Coordination scales were validated in Salanova, et al. (2012). In- and Extra-role Performance: We used an adaptation of the Goodman et al. (1999) scales, reworded at the group level. The group leader assessed in-role performance (3 items; e.g., "The team that I supervise performs all the functions and tasks demanded by the job"; alpha = .92) and extra-role performance (3 items; e.g., "In the team that I supervise, employees perform roles that are not formally required but which improve the organizational reputation"; alpha = .86). Items were scored on a 7- 
point Likert scale ranging from 0 (never) to 6 (always). This scale was validated in Salanova, et al. (2012).

Creative Performance: The construct was assessed by three evaluators using the O'Quin and Besemer (2006) scale. These three evaluators were: one expert (i.e., who had professional expertise about the creativity task) and two researchers (i.e., who were not involved in the study and who received a brief assessment training about creativity). In order to obtain a group creative performance value, first the evaluators assessed the creativity individually in terms of novelty, resolution, and style. Then, the evaluators compared their notes and deliberated. Finally, the evaluators independently assessed the creativity of the group's performance on a 7-point Likert scale ranging from 0 (not at all creative) to 6 (highly creative).

\section{Data analyses}

We computed the means, standard deviations, Cronbach's alpha coefficients, and bivariate correlations for all scales. All variables were measured at the group level as the referent and, in the case of the group positive affect and group social resources measures, aggregated scores were employed for group-level analysis. According to multilevel theory, this is defined as Referent-Shift Consensus Composition (Chan, 1998), meaning that there is a shift in the referent prior to consensus assessment. To statistically demonstrate within-team agreement and between-team differences, we conducted several tests: (1) the Average Deviation Index $\left(\mathrm{AD}_{\mathrm{M}}\right.$; James, Demaree \& Wolf, 1984; Burke, Finkelstein, \& Dusig, 1999) was used to assess within-group agreement; and (2) the Intraclass Correlation Coefficient ( $\mathrm{ICC}_{1}$; Bliese, 2000) was used to assess reliability. Conventionally, an $\mathrm{AD}_{\mathrm{M}}$ equal to or less than 1.2 is considered sufficient evidence of team agreement when items are scored on a 7-point Likert scale 
(LeBreton \& Senter, 2008), whereas values greater than .05 for $\mathrm{ICC}_{1}$ are considered sufficient evidence to justify aggregation (Bliese, 2000). Moreover, an ANOVA $F$ value that is statistically significant is a condition that justifies the aggregation of scores at the group level (Kenny \& LaVoie, 1985). The measures of in- and extra- role performance also have the group as the referent, but they do not have to show agreement because we only have one measure for each group, the one reported by the leader.

In order to exam common method variance, Harman's single factor test (Podsakoff, MacKenzie, Lee, \& Podsakoff, 2003) was carried out using AMOS 21.0 (Arbuckle, 2010) for the variables assessed by the participants (i.e., group positive affect, group social resources).

Finally, we used Structural Equation Modeling (SEM) by AMOS 21.0, using the maximum likelihood estimation method. In order to test the hypotheses, two models were compared: M1, the fully mediated model; M2, the partially mediated model. To test the mediation hypotheses (Hypotheses 4 and 5), we used the product of coefficients method (MacKinnon, Lockwood, et al., 2002), due to the problems associated with the Baron and Kenny (1986) procedure for testing mediation (González-Romá, \& Hernández, 2014). To compare the models tested, two absolute goodness-of-fit indices were assessed: (1) the $\chi^{2}$ goodness-of-fit statistic and (2) the Root Mean Square Error of Approximation (RMSEA). Accordingly, four relative goodness-of-fit indices were used: (1) the Normed Fit Index (NFI); (2) the Tucker-Lewis Index (TLI); (3) the Incremental Fit Index (IFI); and (4) the Comparative Fit Index (CFI). Values below .06 for RMSEA and $p>0.05$ for $\chi^{2}$ indicate a good fit. For the remaining indices, values greater than .90 indicate a good fit, whereas values greater than .95 indicate superior fit (Hu \& Bentler, 1999). We computed the Akaike Information Criterion (AIC; Akaike, 1987) to compare competing non-nested models; the lower the AIC index, the better the fit (Kline, 2011). 
Finally, based on Kline's recommendations (2011), we tested an alternative model (called M3) to make sure that the order of the mediating variables in the model is not arbitrary.

\section{Results}

\section{Preliminary analyses}

Table 1 presents means, standard deviations, internal consistencies (Cronbach's alpha), and bivariate correlations for all variables in the study, individual $(\mathrm{N}=449)$ and group level $(\mathrm{N}=112)$.

Each group positive affect is positively related to the other ones, and the in- and extra-role performances are also positively related. In addition, each group positive affect is positively related to creative performance. Moreover, each group positive affect is positively related to each group social resource, which in turn is positively related to in- and extra- role performance indicators and creative performance (with the exception of the correlation between creative performance and cohesion). In- and extra- role performance are not related to creative performance.

According to our measurements, the average $\mathrm{AD}_{\mathrm{M}}$ value ranged from .53 to .84 . The average $\mathrm{ICC}_{1}$ value ranged from .10 to .46 . One-way ANOVA $F$ values ranged from 1.46 to 32.5 , and they were significant $(p$ entre $<0.005 \mathrm{y}<0.000$ ) for all variables. In conclusion, we found empirical justification for aggregation (Bliese, 2000; LeBreton \& Senter, 2007).

Finally, the results of Harman's test (Podsakoff, et al., 2003) revealed that a onefactor model between group positive affect and group social resources showed a poor fit to the data: $[\chi 2(14)=127.733, \mathrm{p}=.000, \mathrm{RMSEA}=.271, \mathrm{CFI}=.669, \mathrm{NFI}=.810, \mathrm{TLI}$ $=.739, \mathrm{IFI}=.828, \mathrm{AIC}=169.733]$. By contrast, results also showed that the two-factor model fit the data better than a one-factor model: $[\chi 2(13)=24.498, p=.027$, RMSEA 
$=.089, \mathrm{CFI}=.982, \mathrm{NFI}=.964, \mathrm{TLI}=.972, \mathrm{IFI}=.983, \mathrm{AIC}=68.498]$. The difference between the two models is also significant, in favor of the model with two latent factors, $\Delta \chi^{2}(1)=130.235, p<.001$. Consequently, common method variance is not a serious deficiency in these data. Moreover, in order to mitigate common method variance, two procedural remedies were implemented (Podsakoff, MacKenzie, \& Podsakoff, 2012). First, we obtained the measures from different sources (group members, leaders, and evaluators). Second, we differentiated the scale properties shared by the measures of the predictor and mediator variables: group positive affect was scored on a "Faces Scale", whereas group social resources were scored on a "Likert Scale".

\section{PLEASE INSERT TABLE 1 ABOUT HERE}

\section{Hypothesis Testing}

To compute SEM, we used the aggregated database that included group positive affect, group social resources, in-extra- role performance, and creative performance ( $\mathrm{N}=112$ ). According to Brown (2006), in cases where it may be necessary to use single indicators in a SEM analysis, measurement error can be readily incorporated into a dimensional indicator by fixing its unstandardized error to some non-zero value, calculated on the basis of the measure's sample variance estimate and known psychometric information (e.g., internal consistency). Thus, we fixed the unstandardized error of the indicator of creative performance with the formula: variance*(1-alpha).

Table 2 shows the results of the SEM analysis. We expected full mediation by group social resources between group positive affect and group performance (in- extrarole performance and creative performance); thus, we tested the full mediation research model (M1). The path from group positive emotions to group social resources was 
positive and statistically significant $(\beta=.72, p<.001)$, as was the path from group social resources to in- extra- role performance $(\beta=.46, p<.001)$ and creative performance $(\beta=.25, p<.05)$. This finding supported our Hypotheses 1,2 and 3 .

In order to test the mediation hypotheses (Hypotheses 4 and 5), we estimated the product of coefficients method (MacKinnon, et al., 2002). The mediated effect of Hypothesis 4 (group positive affect $\rightarrow$ group social resources $\rightarrow$ in-extra- role performance) was statistically significant $\left(\mathrm{P}=\mathbf{Z}_{\boldsymbol{\alpha}} \cdot \mathbf{Z}_{\boldsymbol{\beta}}=31.38, p<0.05\right)$, as was the mediated effect of Hypothesis 5 (group positive affect $\rightarrow$ group social resources $\rightarrow$ creative performance; $\mathrm{P}=\mathbf{Z}_{\boldsymbol{\alpha}} \cdot \mathbf{Z}_{\boldsymbol{\beta}}=8.11, p<0.05$ ). However, the direct or nonmediated effect between group positive affect and in-extra- role performance was not statistically significant $(\mathbf{T}=.065, \mathrm{~ns})$, or between group positive affect and creative performance $(\mathbf{T}=.292$, ns). These results suggest a full mediation effect of group social resources between group positive affect and both group performances, in-extra-role performance and creative performance (see Figure 3). This finding supported our Hypotheses 4 and 5. Furthermore, the chi-square difference test between M1 (the Fully Mediated model) and M2 (the Partially Mediated model) shows a non-significant difference between the two models, $\Delta \chi^{2}(2)=1.24$, ns, which is to be interpreted in favor of the most parsimonious one, namely M1. Comparing the two models, M1 showed the lowest AIC value.

\section{Alternative Models}

To lend more credibility to our cross-sectional findings, we tested an additional competitive model (M3). Considering that it is also conceivable that group positive emotions fully mediate the relationship between group social resources and group performance (i.e., in- and extra-role performance, creative performance), based on the 
Job Demands-Resources model, which posits that employees' working conditions (i.e., job resources) are related to their psychosocial wellbeing, which in turn is associated with several outcomes (Demerouti, et al., 2001). When the models to be compared are not nested models, a fit index used to compare their fit is AIC (Akaike, 1987; Kline, 2011). Although the data fit M3 well, M1 showed the lowest AIC value; therefore, M1 is better than M3.

It is interesting to note that in M1, group positive affect explains $52.3 \%$ of the variance in group social resources $\left(\mathrm{R}^{2}=.528\right)$, which in turn explains $21 \%$ of the variance in in- and extra-role performance $\left(\mathrm{R}^{2}=.210\right)$ and $6.3 \%$ of the variance in creative performance $\left(\mathrm{R}^{2}=.063\right)$. The final model is depicted in Figure 3.

\title{
PLEASE INSERT TABLE 2 ABOUT HERE \\ PLEASE INSERT FIGURE 3 ABOUT HERE
}

\section{STUDY 2}

The second study is a field study with employees and supervisors from several organizations. According to previous research on the Broaden and Build Theory, we expect group positive affect to be positively related to group social resources (Hypothesis 1). Furthermore, we expect group social resources to be positively associated with group performance (i.e., in-extra role performance) (Hypothesis 2). Finally, we sought to uncover whether group social resources fully mediate the relationship between group positive affect and group performance (i.e., in- and extrarole performance) (Hypothesis 3). The Study 2 model is displayed in Figure 4.

\author{
PLEASE INSERT FIGURE 4 ABOUT HERE
}


HOW POSITIVE AFFECT LINKS TO PERFORMANCE

\section{Method}

\section{Sample and Procedure}

The sample consisted of 2,159 employees nested in 417 teams from 129 companies in Spain. In all, 97 companies belonged to the service sector, 26 to industry, and five to construction. Moreover, $52.8 \%$ were male, $82.4 \%$ had an indefinite contract, $15 \%$ had a temporary contract, and $3.6 \%$ had other types of work situations (e.g., substitution, freelance). Average tenure in the company was 16.81 months ( $\mathrm{SD}=$ 42.078).

Regarding the supervisors, $59.9 \%$ were male, $87.4 \%$ had an indefinite contract, $1.5 \%$ had a temporary contract, and $11.1 \%$ had other working arrangements. The average tenure in the company was 31.99 months $(\mathrm{SD}=124.87)$.

Finally, the group size ranged from 2 to 35 employees, with an average of 5.14 $(\mathrm{SD}=4.4)$

In order to collect the data, we contacted the key stakeholders in each organization (i.e., CEOs, Human Resources Managers) to provide them with details about the purpose and requirements of the study. After that, we administered the questionnaires to the participants. Employees were considered members of a group when they interacted often, shared job goals, had interdependent tasks, and had the same supervisor. In addition, the supervisor had to be responsible for the productivity and actions of the group.

\section{Measures}

In Study 2, we used identical measures to those used for employees in Study 1; however, and due to specific characteristics of the sample and study, we made several changes: 1) Considering that the literature defines mood as a diffuse feeling that is not focused on a specific target (Frijda, 1986; Tellegen, 1985), we measured group positive 
affect as representing how the group felt during the past year at work. The alpha of the scale was .93; 2) We did not evaluate cohesion as a group social resource, but instead we evaluated supportive team climate (3 items, i.e., "In my team, constructive criticism is rewarded"; alpha $=.85$ ). The scale was taken from Van Muijen et al. (1999) and validated in Salanova et al. (2009); and 3) In order to obtain external performance, inand extra-role performance were evaluated by the supervisor, who was responsible for the productivity and actions of group. Cronbach's alphas for the aggregated scores are listed on the diagonal in parentheses (see Table 3).

\section{Data analyses}

We performed the same analyses as in Study 1.

\section{Results}

\section{Preliminary analyses}

Table 3 presents means, standard deviations, internal consistencies (Cronbach's alpha), and bivariate correlations for all the variables in study 2 , individual $(\mathrm{N}=2,159)$ and group level $(\mathrm{N}=417)$.

Each group positive affect is positively related to the other ones, and group inextra- role performances are also positively related. Moreover, each group positive affect is positively related to each group social resource, which in turn is positively related to in-extra- role performance indicators.

According to our measurements, the average $\mathrm{AD}_{\mathrm{M}}$ value ranged from .87 to 1.2. The average $\mathrm{ICC}_{1}$ value ranged from .13 to .23 . One-way ANOVA $F$ values ranged from 1.8 to 2.53 , and they were significant $(p<0.000)$ for all variables. In conclusion, we found empirical justification for aggregation (Bliese, 2000; LeBreton et al., 2007). 
Finally, the results of Harman's test (Podsakoff, et al., 2003) revealed that the one-factor model between group positive affect and group social resources showed a poor fit to the data: $[\chi 2(14)=403.041, p=.000, \mathrm{RMSEA}=.258, \mathrm{CFI}=.814, \mathrm{NFI}$ $=.814, \mathrm{TLI}=.728, \mathrm{IFI}=.819, \mathrm{AIC}=445.041]$. By contrast, results also showed that the two-factor model fit the data better than a one-factor model: $\left[\chi^{2}(13)=50.312, p=.000\right.$, $\mathrm{RMSEA}=.083, \mathrm{CFI}=.983, \mathrm{NFI}=.977, \mathrm{TLI}=.972, \mathrm{IFI}=.983, \mathrm{AIC}=94.312]$. The difference between the two models is also significant, in favor of the model with two latent factors, $\Delta \chi 2(1)=352.729, p<.001$. Consequently, common method variance is not a serious deficiency in these data. Moreover, in order to mitigate common method variance, we implemented the same procedural remedies as in study 1 .

\section{PLEASE INSERT TABLE 3 ABOUT HERE}

\section{Hypothesis Testing}

To compute SEM, we used the aggregated database that included group positive affect, group social resources, and in- and extra- role performance $(\mathrm{N}=417)$.

Table 4 shows the results of the SEM analysis. We expected full mediation by group social resources between group positive affect and in-extra- role performance, and so we tested the full mediation research model (M1). The path from group positive affect to group social resources was positive and statistically significant $(\beta=.598, p$ $<.001$ ), as was the path from group social resources to in- and extra- role performance $(\beta=.294, p<.001)$. This finding supported our Hypotheses 1 and 2 .

In order to test the mediation hypothesis (Hypothesis), we estimated the product of coefficients method (MacKinnon et al., 2002). The mediated effect was statistically significant $\left(\mathrm{P}=\mathrm{Z}_{\alpha} \cdot \mathrm{Z}_{\beta}=40.67, p<.001\right)$. However, the direct or non-mediated effect 
between group positive affect and in- and extra-role performance was not statistically significant $(\mathrm{T}=.044, \mathrm{~ns})$. Furthermore, the chi-square difference test between M1 (the Fully Mediated model) and M2 (the Partially Mediated model) shows a non-significant difference between the two models, $\Delta \chi^{2}(1)=.01$, ns, which is to be interpreted in favor of the most parsimonious one, namely M1. Comparing the two models, M1 showed the lowest AIC value. These results suggest a full mediation effect of group social resources between group positive affect and in- and extra-role performance (see Figure 4). This finding supported our Hypothesis 3.

\section{Alternative Models}

To lend more credibility to our cross-sectional findings, we tested an additional competitive model (M3). Considering that it is also conceivable that group positive emotions fully mediate the relationship between group social resources and group performance (i.e., in- and extra-role performance), based on the Job DemandsResources model, which posits that employees' working conditions (i.e., job resources) are related to their psychosocial wellbeing, which in turn is associated with several outcomes (Demerouti, et al., 2001). When the models to be compared are not nested models, a fit index used to compare the fit of statistical models is AIC (Akaike, 1987; Kline, 2011). Although the data fit M3 well, M1 showed the lowest AIC value; therefore, M1 is better than M3.

It is interesting to note that in M1, group positive emotions explain $35.8 \%$ of the variance in group social resources $\left(\mathrm{R}^{2}=.358\right)$, which in turn explains $8.7 \%$ of the variance in in- and extra-role performance $\left(\mathrm{R}^{2}=.087\right.$. The final model is depicted in Figure 5. 
HOW POSITIVE AFFECT LINKS TO PERFORMANCE

\author{
PLEASE INSERT TABLE 4 ABOUT HERE \\ PLEASE INSERT FIGURE 5 ABOUT HERE
}

\begin{abstract}
Discussion
This paper contributes to the literature on the happy-productive group by examining the processes (i.e., group social resources) underlying the relationships between group positive affect and group performance. Based on B\&B theory (Fredrickson, 1998; 2001), we hypothesized and found that group positive affect builds group social resources, which trigger group performance, in- and extra-role performance (study 1 and study 2), and creative performance (study 1).

The results supported our hypotheses, indicating that group positive affect (i.e., enthusiasm, optimism, satisfaction, comfort) was positively related to group social resources (i.e., teamwork, coordination, cohesion, supportive team climate), confirming Hypothesis 1 (study 1 and study 2). On the other hand, group positive resources were positively related to in- and extra-role performance reported by the leader/supervisor (confirming Hypothesis 2, study 1 and study 2) and creative performance reported by evaluators (confirming Hypothesis 3, study 1). Moreover, our study demonstrated significant mediation paths through group social resources. Specifically, it was revealed that group social resources fully mediate the effects of group positive affect on in- and extra-role performance (confirming Hypothesis 4, study 1, and confirming Hypothesis 3, study 2), and creative performance (confirming Hypothesis 5, study 1). Results from study 1 revealed that in- and extra-role performances were not positively related to creative performance. The reason could be that we evaluated the same phenomenon (i.e., design a poster that promoted a toy), but we used different units of measurement.
\end{abstract}




\section{Theoretical Contributions}

This study makes a number of contributions to the positive psychology literature by providing additional evidence about the functions of group positive emotions. First, the B\&B theory of positive emotions (Fredrickson, 1998, 2001) proposes that positive emotions increase social resources such as social support and connections among people. The present study expands this hypothesis to collective levels of analysis (i.e., small groups), and we propose that social resources (i.e., teamwork, coordination, cohesion, supportive team climate) are built as a result of social interactions among members.

Second, this study advances group performance research by identifying interaction processes underlying the positive affect-performance relationship in groups. In several ways, our results expand Rhee's study showing that social interactions among group members (e.g., building ideas, building communication) mediate the relationship between positive affect and group performance (e.g., creativity): 1) Following the Circumplex model (Russell, 1980; Warr, 1990), our study has considered a wide range of group positive affects (i.e., enthusiasm, optimism, satisfaction, comfort), and not only group joy; 2) We have identified one of the mechanisms that explain the relationship between group positive affect and group performance: group social resources (i.e., teamwork, coordination, cohesion, supportive team climate). However, it is important to notice that not always a happy group is also productive as well, because it depends on variables such as social resources that the group used in order to perform well. In that sense, positive affect allows the group to behave in a more flexible, creative, and open way and being more motivated to explore new behaviours; 3) In order to obtain a comprehensive view of group performance, we have considered complementary types 
of job performance (i.e., in-role, extra-role); 4) The model was tested in a field study, not only in a laboratory study.

Although the study of the happy-productive worker thesis is extensive, the study of an analogous model at the group level is not (i.e., happy-productive group). The present study advances the construct of the happy-productive group by showing an analogous psychosocial process where happy groups (i.e. sharing more collective positive emotions among group members) are also more productive because they have better in- and extra-role performance and more creative behaviors.

Finally, the results of this study support the statement by Gable et al. (2008) about the similar effects of positive mood and positive emotions on behaviors and cognitions. We considered positive emotions in study 1 as task output, whereas positive mood in study 2 was studied as a positive feeling at work. Although the operationalization of the psychological constructs are different, the findings are quite similar, showing that our results are robust.

\section{Practical Implications}

Although the relevance of positive affect in organizations is not new (Barsade et al., 2007), organizations should care about and focus on employees' emotions, as well as group emotions. Positive leaders have to effectively manage cognitive aspects of team members, but also their emotional factors, which positively influence organizational outcomes (Ashkanasy, Härtel \& Daus, 2002). For instance, Cruz-Ortiz, Salanova, and Martínez (2017) found that supervisors who developed a transformational leadership style increased group and individual performance only when they managed the group and individual positive emotions. This is because transformational leaders 
motivate and intellectually stimulate their followers, encourage pride, trigger enthusiasm, and transmit optimism about a desirable future (Ashkanasy \& Tse, 2000).

Results from the present study suggest a promising direction for interventions to increase group positive affect. For example, HRM strategies could also be used to proactively build positive emotional experiences for organizational members. Moreover, "positive emotions hold a distinctly social origin, such that interacting with others is a common platform for emotions to arise" (Vacharkulksemsuk et al., 2013, pp 51.). Along the lines of our results, these conclusions suggest that interventions should be focused on the group, rather than individually.

Finally, creativity in organizations implies a value added that the competition cannot copy. Results propose that enhancement of group positive affect seems to be the key to facilitating creativity, but it is also important to take care of the group's perceptions of social resources.

\section{Limitations and Future Research}

Despite obtaining interesting results, the present study has several limitations. A first limitation is that a non-probabilistic sample (i.e., convenience) was used, which might restrict the generalizability of these findings. However, the study 2 sample is a heterogeneous sample because it includes different groups from different companies with different sources of information (i.e., employees, supervisors), which allows us to obtain a view of the reality of the organization.

Second, some data were obtained from self-report measures (i.e., group positive affect, group social resources), which might have caused common method bias. However, given the nature of this study, which includes psychological experiences such as group positive emotions and group social resources, it is difficult to use objective 
data. Moreover, Harman's test suggests that common method variance should not be a major threat to the validity of our study. Finally, the use of external raters (in study 1 , leader and evaluators, and in study 2, supervisor) of group performance is a strong point of this study that adds to the robustness of our findings, although we also understand that performance assessment by leaders might be biased.

Third, the idea that group positive affect emerges through social interaction is supported by different mechanisms, such as emotional contagion (Hatfield, Cacioppo \& Rapson, 1992), empathy (Nelson, Klein \& Irvin, 2003), similar group member reactions to shared events (Weiss \& Cropanzano, 1996), and activating a group social identity (Seger, Smith \& Mackie, 2009). Although in the current paper we did not consider these mechanisms, future studies should further analyze the underlying mechanisms that lead to shared affect among group members.

Fourth, although our research focused on documenting that group positive emotions start the process of the B\&B theory, future research should examine the specific potential of group discrete emotions (e.g., joy, relaxation) on specific group action tendencies (Mackie, Smith \& Ray, 2008). Moreover, we should consider that different jobs with specific action tendencies could lead to specific discrete emotions.

In addition, because group positive affect also has beneficial outcomes for individuals and groups in the organizational context (Fredrickson, 2003), it is important to identify its potential antecedents, such as healthy organizational practices.

A final limitation of the present study is that the data are cross-sectional. Although SEM analysis, specifically the proposed M3, provides some information about the possible direction of the relationships, cross-sectional study designs do not allow us to draw firm conclusions about the causal ordering among the variables 
studied. Thus, future research should focus on developing longitudinal studies with experimental designs in order to uncover the causal order among the study variables.

\section{Final Note}

This study adds to the growing literature on B\&B theory at the group level and the happy-productive group thesis. It advances the knowledge in this area because it contemplates group social resources as a mechanism that connects group positive affect to group outcomes, such as achieving task goals. The main strength of this study is the use of leaders/supervisors' ratings and evaluators' ratings to assess performance. The findings indicate that happy groups are productive groups when they are able to develop aspects related to interpersonal dynamics.

\section{Disclosure statement}

No potential conflict of interest was reported by the authors

\section{Funding}

This work was supported by grants from the Universitat Jaume I [\#PREDOC/2014/56] and [\#E/2016/29]; Spanish Ministry of Economy and Competitiveness [\#PSI201564933-R]; and Consellería de Educación Generalitat Valenciana [\#PROMETEO/2013/025]. 


\section{References}

Akaike, H. (1987). Factor analysis and AIC. Psychometrika, 52, 317-332.

Amabile, T. (n.d.). How to Kill Creativity. Creative Management and Development Creative Management and Development, 18-24. doi:10.4135/9781446213704.n2

Amabile, T. M. (1996). Creativity in Context. Boulder, CO: Westview Press

Amabile, T. M. (1997). Motivating Creativity in Organizations: On Doing What You Love and Loving What You Do. California Management Review, 40(1), 39-58. doi: $10.2307 / 41165921$

Amabile, T. M., \& Pratt, M. G. (2016). The dynamic componential model of creativity and innovation in organizations: Making progress, making meaning. Research in Organizational Behavior, 36, 157-183. doi:10.1016/j.riob.2016.10.001”

Arbuckle, J. L. (2010). IBM SPSS Amos 19 users' guide. Chicago, IL: SPSS.

Ashkanasy, N. M., \& Tse, B. (2000). Transformational leadership as management of emotion: A conceptual review. In N. M. Ashkanasy, C. E. J. Hartel, \& W. J. Zerbe (Eds.), Emotions in the workplace: Theory, research and practice (221 235). Westport, CT: Quorum Books

Ashkanasy, N. M., Härtel, C. E. J, \& Daus, C. S. (2002). Diversity and Emotion: The New Frontiers in Organizational Behavior Research. Journal of Management, 28(3), 307-338. doi:10.1177/014920630202800304

Baas, M., De Dreu, C. K., \& Nijstad, B. A. (2008). A meta-analysis of 25 years of mood-creativity research: Hedonic tone, activation, or regulatory focus?. Psychological bulletin, 134(6), 779-806. doi:10.1037/a0012815 
Baron, R. M., \& Kenny, D. A. (1986). The moderator-mediator variable distinction in social psychological research: Conceptual, strategic, and statistical considerations. Journal of Personality and Social Psychology, 51(6), 11731182. doi:10.1037/0022-3514.51.6.1173

Barsade, S. G., \& Gibson, D. E. (1998). Group emotion: A view from top and bottom. Research on managing groups and teams, 1(4), 81-102.

Barsade, S. G., \& Gibson, D. E. (2007). Why does affect matter in organizations?. The Academy of Management Perspectives, 21(1), 36-59. doi:10.5465/amp.2007.24286163

Barsade, S. G., \& Gibson, D. E. (2012). Group affect: Its influence on individual and group outcomes. Current Directions in Psychological Science, 21(2), 119-123. doi:10.1177/0963721412438352

Barsade, S. G., \& Knight, A. P. (2015). Group Affect. Annual Review of Organizational Psychology and Organizational Behavior, 2(1), 21-46. doi:10.1146/annurevorgpsych-032414-111316

Beal, D. J., Cohen, R. R., Burke, M. J., \& McLendon, C. L. (2003). Cohesion and Performance in Groups: A Meta-Analytic Clarification of Construct Relations. Journal of Applied Psychology, 88(6), 989-1004. doi:10.1037/00219010.88.6.989

Bliese, P. D. (2000). Within-group agreement, non-independence, and reliability: Implications for data aggregation and analysis. In K. J. Klein, S. J. Kozlowski, K. J. Klein, S. J. Kozlowski (Eds.), Multilevel theory, research, and methods in organizations: Foundations, extensions, and new directions (349-381). San Francisco, CA US: Jossey-Bass. 
Brown, T.A. (2006). Confirmatory factor analysis for applied research. New York, NY US: Guilford Press

Burke, N. J., Finkelstein, L. M., \& Dusig, M. S. (1999). On average deviation indices for estimating interrater agreement. Organizational Research Methods, 2, 49-68. doi:10.1177/109442819921004

Chan, D. (1998). Functional relations among constructs in the same content domain at different levels of analysis: A typology of composition models. Journal of Applied Psychology, 83(2), 234-246. doi:10.1037/0021-9010.83.2.234.

Chi, N.-W., Chung, Y.-Y., \& Tsai, W.-C. (2011). How Do Happy Leaders Enhance Team Success? The Mediating Roles of Transformational Leadership, Group Affective Tone, and Team Processes. Journal of Applied Social Psychology, 41(6), 1421-1454. doi:10.1111/j.1559-1816.2011.00767.x

Cohen, S. G., \& Bailey, D. E. (1997). What makes teams work: Group effectiveness research from the shop floor to the executive suite. Journal of Management, 23(3), 239-290. doi:10.1016/s0149-2063(97)90034-9

Connolly, T., Jessup, L. M., \& Valacich, J. S. (1990). Effects of anonymity and evaluative tone on idea generation in computer-mediated groups. Management Science, 36(6), 689-703. doi:10.1287/mnsc.36.6.689

Cruz-Ortiz, Salanova, \& Martínez (2017). A Multilevel Study of how Transformational Leadership predicts Positive Emotions and Job Performance. Manuscript in preparation.

Demerouti, E., Bakker, A.B., Nachreiner, F. \& Schaufeli, W.B. (2001). The Job Demands-Resources model of burnout. Journal of Applied Psychology, 86(3), 499-512. doi:10.1037/0021-9010.86.3.499 
Diener, E., \& Oishi, S. (2005). The nonobvious social psychology of happiness. Psychological Inquiry, 16(4), 162-167.doi:10.1207/s15327965pli1604_04

Fernández-Abascal, E. G. (2009). Emociones positivas. Madrid: Ediciones Pirámide

Fisher, C. D., \& Ashkanasy, N. M. (2000). The emerging role of emotions in work life: An introduction. Journal of Organizational Behavior, 21, 123-129

Fredrickson, B. L. (1998). What good are positive emotions? Review of General Psychology: Special Issue: New Directions in Research on Emotion, 2, 300-319.

Fredrickson, B. L. (2001). The role of positive emotions in positive psychology: The broaden-and-build theory of positive emotions. American Psychologist: Special Issue, 56, 218-226.

Fredrickson, B. L. (2003). Positive emotions and upward spirals in organization. In K. Cameron, J. Dutton, \& R. Quinn (Eds.), Positive organizational scholarship. (pp. 163-175). San Francisco, CA: Berrett-Koehler.

Fredrickson, B. L. (2013). Positive emotions broaden and build. Advances in experimental social psychology, 47, 1-53.

Fredrickson, B. L., \& Losada, M. F. (2005). Positive Affect and the Complex Dynamics of Human Flourishing. American Psychologist, 60(7), 678-686. doi:10.1037/0003-066x.60.7.678

Fredrickson, B.L., \& Cohn, M.L. (2008). Positive Emotions. In Lewis, M., HavilandJones, J. M., y Barrett, L. F. (Eds.).(2008). Handbook of emotions. (777-796). New York: Guilford Press.

Frijda, N.H. (1986). The emotions. Cambridge, UK: Cambridge University Press

Gable, P.A. \& Harmon-Jones, E. (2008). Approach-motivated positive affect reduces breadth of attention. Psychological Science, 19, 476-482 
Gilson, L. L., \& Shalley, C. E. (2004). A Little Creativity Goes a Long Way: An Examination of Teams' Engagement in Creative Processes. Journal of Management, 30(4), 453-470. doi:10.1016/j.jm.2003.07.001

Gilson, L. L., Mathieu, J. E., Shalley, C. E., \& Ruddy, T. M. (2005). Creativity and standardization: complementary or conflicting drivers of team effectiveness?. Academy of Management Journal, 48(3), 521-531. doi:10.5465/amj.2005.17407916

González-Romá, V., \& Gamero, N. (2012). Does positive team mood mediate the relationship between team climate and team performance?. Psicothema, 24(1), 94-99.

González-Romá, V., \& Hernández, A. (2014). Climate uniformity: Its influence on team communication quality, task conflict, and team performance. Journal of Applied Psychology, 99(6), 1042-1058. doi:10.1037/a0037868

Goodman, S. A., \& Svyantek, D. (1999). Person-organization fit and contextual performance: Do shared values matter. Journal of Vocational Behavior, 55, 254275.

Hatfield, E., Cacioppo, J., \& Rapson, R. L. (1994). Emotional contagion. New York: Cambridge University Press.

Hu, L., \& Bentler, P. M. (1999). Cutoff criteria for fit indexes in covariance structure analysis: Conventional criteria versus new alternatives. Structural Equation Modeling, 6(1), 1-55. doi:10.1080/10705519909540118.

Hülsheger, U. R., Anderson, N., \& Salgado, J. F. (2009).Team-level predictors of innovation at work: a comprehensive meta-analysis spanning three decades of research.Journal of Applied psychology, 94(5), 1128. 
James, L. R., Demaree, R. G., \& Wolf, G. (1984). Estimating within-group interrater reliability with and without response bias. Journal of Applied Psychology, 69(1), 85-98. doi:10.1037/0021-9010.69.1.85

Kelly, J. R., \& Spoor, J. R. (2006). Affective influence in groups. In J. P. Forgas (Ed.), Affect in social thinking and behavior (311-325). New York: Psychology Press.

Kelly, J. R., \& Spoor, J. R. (2013). Affective processes. In J. M. Levine (Ed.). Group processes, 33-53. New York: Psychology Press.

Kelly, J.R., \& Barsade, S.G. (2001). Mood and emotions in small groups and work teams. Organizational Behaviour and Human Decision Processes, 86, 99-130

Kenny, D. A., \& LaVoie, L. (1985). Separating individual and group effects. Journal of Personality and Social Psychology, 48(2), 339-348. doi:10.1037/00223514.48 .2 .339

Kline, R. B. (2011). Principles and practice of structural equation modeling. New York: Guilford press.

Knight, A. P., \& Eisenkraft, N. (2014). Positive is usually good, negative is not always bad: The effects of group affect on social integration and task performance. Journal of Applied Psychology, 100(4), 1214-1227. doi:10.1037/ap10000006

Kok, B. E., \& Fredrickson, B. L. (2010). Upward spirals of the heart: Autonomic flexibility, as indexed by vagal tone, reciprocally and prospectively predicts positive emotions and social connectedness. Biological psychology, 85(3), 432436.

Kok, B. E., Coffey, K. A., Cohn, M. A., Catalino, L. I., Vacharkulksemsuk, T., Algoe, S. B., Brantley, M., \& Fredrickson, B. L. (2013). How positive emotions build physical health: Perceived positive social connections account for the upward 
spiral between positive emotions and vagal tone. Psychological Science, 24, $1123-1132$.

Kunin, T. (1955).The construction of a new type of attitude measure. Personnel Psychology, 8, 65-67.

Lazarus, R. S. (1991). Emotion and adaptation. New York: Oxford University Press

LeBreton, J. M., \& Senter, J. L. (2008). Answers to 20 Questions About Interrater Reliability and Interrater Agreement. Organizational Research Methods, 11(4), 815-852. doi:10.1177/1094428106296642

Lewis, M., Haviland-Jones, J. M., \& Barrett, L. F. (3 Eds.).(2010). Handbook of emotions. Guilford Press.

Lyubomirsky, S., King, L., \& Diener, E. (2005). The benefits of frequent positive affect: Does happiness lead to success? Psychological Bulletin, 131, 803855.

Mackie, D. M., Smith, E. R., \& Ray, D. G. (2008). Intergroup Emotions and Intergroup Relations. Social and Personality Psychology Compass, 2(5), 1866-1880. doi:10.1111/j.1751-9004.2008.00130.x

MacKinnon, D. P., Lockwood, C. M., Hoffman, J. M., West, S. G., \& Sheets, V. (2002). A comparison of methods to test mediation and other intervening variable effects. Psychological Methods, 7(1), 83-104. doi:10.1037/1082-989x.7.1.83

Mauss, I. B., Shallcross, A. J., Troy, A. S., John, O. P., Ferrer, E., Wilhelm, F. H., \& Gross, J.J. (2011). Don’t hide your happiness! Positive emotion dissociation, social connectedness, and psychological functioning. Journal of Personality and Social Psychology, 100(4), 738-748. 
Meneghel, I., Martínez, I. M., \& Salanova, M. (2016). Job-related antecedents of team resilience and improved team performance. Personnel Review, 45(3), 505-522. doi:10.1108/pr-04-2014-0094

Meneghel, I., Salanova, M., \& Martínez, I. M. (2014). Feeling Good Makes Us Stronger: How Team Resilience Mediates the Effect of Positive Emotions on Team Performance. Journal of Happiness Studies, 17(1), 239-255. doi:10.1007/s10902-014-9592-6

Mullen, B., \& Copper, C. (1994). The relation between group cohesiveness and performance: An integration. Psychological Bulletin, 115(2), 210-227. doi:10.1037/0033-2909.115.2.210

Nelson, D., Klein, C. F., \& Irvin, J. E. (2003). Motivational Antecedents of Empathy: Inhibiting Effects of Fatigue. Basic \& Applied Social Psychology, 25(1), 37-50.

O’Bannon, D. P., \& Pearce, C. L. (1999). An exploratory examination of gainsharing in service organizations: Implications for organizational citizenship behavior and pay satisfaction. Journal of Managerial Issues, 11(3), 363-378.

O'Quin, K., \& Besemer, S. P. (2006). Using the Creative Product Semantic Scale as a Metric for Results-Oriented Business. Creativity and Innovation Management, 15(1), 34-44. doi:10.1111/j.1467-8691.2006.00367.x

Oh, H., Chung, M. H., \& Labianca, G. (2004). Group social capital and group effectiveness: The role of informal socializing ties. Academy of Management Journal, 47(6), 860-875.

Podsakoff, P. M., MacKenzie, S. B., \& Podsakoff, N. P. (2012). Sources of method bias in social science research and recommendations on how to control it. Annual Review of Psychology, 63(1), 539-569. doi:10.1146/annurev-psych-120710100452. 
Podsakoff, P. M., MacKenzie, S. M., Lee, J., \& Podsakoff, N. P. (2003). Common method variance in behavioral research: A critical review of the literature and recommended remedies. Journal of Applied Psychology, 88, 879-903.

Price, J.L. \& Mueller, C.W. (1986). Handbook of Organizational Measurement. Scranton: Harper Collins. Price, L.L. y Mueller, C.W. (1986). Index of work group cohesion, 252-253

Rhee, S. Y. (2006). Shared emotions and group effectiveness: The role of broadeningand-building interactions. In Proceedings of the Sixty-fifth Annual Meeting of the Academy of Management, 1-40, August 1, 2006 2006:1 B1-B6; http://dx.doi.org/10.5465/AMBPP.2006.22898617

Rhee, S. Y. (2007). Group emotions and group outcomes: The role of group-member interactions. Research on managing groups and teams, 10, 65-95. doi:10.1016/s1534-0856(07)10004-9

Rhee, S., \& Yoon, H. (2012-11-21). Shared Positive Affect in Workgroups. Oxford Handbooks Online. Retrieved 3 Apr. 2017, from http://www.oxfordhandbooks.com/view/10.1093/oxfordhb/9780199734610.001. 0001/oxfordhb-9780199734610-e-017.

Rodríguez-Sánchez, A. M., Devloo, T., Rico, R., Salanova, M., \& Anseel, F. (2016). What Makes Creative Teams Tick? Cohesion, Engagement, and Performance Across Creativity Tasks: A Three-Wave Study. Group \& Organization Management. doi:10.1177/1059601116636476

Russell, J. A. (1980). A circumplex model of affect. Journal of Personality and Social Psychology, 39(6), 1161-1178. doi:10.1037/h0077714

Salanova, M., Bakker, A. B., \& Llorens, S. (2006). Flow at work: Evidence for an upward spiral of personal and organizational resources. Journal of Happiness 
Studies, 7(1), 1-22.

Salanova, M., Cifre, E., Llorens, S., Martínez, I. M., \& Lorente, L. (2011). Psychosocial risks and positive factors among construction workers. In R. Burke, S. Clarke, y C. Cooper (Eds.), Occupational health and safety: Psychological and behavioral challenges (pp. 295-322). Surrey, UK: Gower

Salanova, M., Llorens, S., Cifre, E., \& Martínez, I. M. (2012). We Need a Hero! Toward a Validation of the Healthy and Resilient Organization (HERO) Model. Group \& Organization Management, 37(6), 785-822. doi:10.1177/1059601112470405

Sánchez Pérez, José (2006). Fundamentos de trabajo en equipo para equipos de trabajo. (1ª.ed.). España: McGraw-Hill/Interamericana de España, S.A.U.

Seger, C. R., Smith, E. R., \& Mackie, D. M. (2009). Subtle activation of a social categorization triggers group-level emotions. Journal of Experimental Social Psychology, 45(3), 460-467. doi:10.1016/j.jesp.2008.12.004

Semmer, N. K., \& Beehr, T. A. (2014). Job control and social aspects of work. In M. C. W. Peeters, J. de Jonge, \& T. W. Taris, T. (Eds). An introduction to contemporary work psychology (171-195). Chichester, UK: Wiley Blackwell.

Shin, Y. (2014). Positive Group Affect and Team Creativity. Small Group Research, 45(3), 337-364. doi:10.1177/1046496414533618

Spoor, J. R., \& Kelly, J. R. (2004). The evolutionary significance of affect in groups: Communication and group bonding. Group Processes \& Intergroup Relations, 7, 398 - 412. http://dx.doi.org/10.1177/1368430204046145

Stout, R. J., Salas, E., \& Carson, R. (1994). Individual task proficiency and team process behavior: What's important for team functioning?. Military psychology, $6(3), 177$. 
Sun, W., Xu, A., \& Shang, Y. (2012). Transformational leadership, team climate, and team performance within the NPD team: Evidence from China. Asia Pacific Journal of Management, 31(1), 127-147. doi:10.1007/s10490-012-9327-3

Sy, T., Côté, S., \& Saavedra, R. (2005). The contagious leader: impact of the leader's mood on the mood of group members, group affective tone, and group processes. Journal of applied psychology, 90(2), 295.

Taggar, S., \& Ellis, R. (2007). The role of leaders in shaping formal team norms. The Leadership Quarterly, 18(2), 105-120. doi:10.1016/j.leaqua.2007.01.002

Tellegen, A. (1985). Structures of mood and personality and their relevance to assessing anxiety, with an emphasis on self-report. In A.H. Tuma, \& J.D. Maser (Eds.), Anxiety and the anxiety disorders (pp. 681-706). Hillsdale, NJ: Erlbaum.

Torrente, P., Salanova, M., Llorens, S., \& Schaufeli, W. B. (2012). Teams make it work: How team work engagement mediates between social resources and performance in teams. Psicothema, 24(1), 106-112.

Vacharkulksemsuk, T. (August, 2013). Positive emotions, team cohesion, and performance: A structural equation model of student work teams. International Society for Research on Emotion. Berkeley, CA.

Vacharkulksemsuk, T., \& Fredrickson, B. L. (2013). One decade later: An update of the broaden-andbuild theory of positive emotions in organizations. In A. B. Bakker (Ed.) Advances in Positive Organizational Psychology, Vol. 1. UK: Emerald

Van der Schalk, J., Fischer, A., Doosje, B., Wigboldus, D., Hawk, S., Rotteveel, M., \& Hess, U. (2011). Convergent and divergent responses to emotional displays of ingroup and outgroup. Emotion, 11(2), 286-298. doi:10.1037/a0022582 
Van Emmerik, I.H. \& Brenninkmeijier, V. (2009). Deep-level similarity and group social capital: Associations with team functioning. Small Group Research, 40, 650-669

Van Kleef, G. A., Homan, A. C., \& Cheshin, A. (2012). Emotional influence at work: Take it EASI. Organizational Psychology Review, 2(4), 311-339. doi: $10.1177 / 2041386612454911$

Van Muijen, J. J., Kopman, P., De Witte, K., De Cock, G., Susanj, Z., Lemoine, F., \& Turnipseed, D. (1999). Organizational culture: The FOCUS questionnaire. European Journal of Work and Organizational Psychology, 8, 551-568. doi:10.1080/135943299398168

Wagner, J. A. (1995). Studies of individualism-collectivism: Effects on cooperation in groups. Academy of Management journal, 38(1), 152-173.

Warr, P. (1990). The measurement of well-being and other aspects of mental health. Journal of Occupational Psychology, 63, 193-2

Weiss, H.M., \& Cropanzano, R. (1996). Affective events theory: a theoretical discussion of the structure, causes and consequences of affective experiences at work. In B. M. Staw \& L. L. Cummings (Eds.), Research in organizational behavior (8, pp. 1-74). Greenwich, CT: JAI Press.

Wright, T. A., \& Cropanzano, R. (2007). The happy/productive worker thesis revisited. Research in personnel and human resources management, 26, 269-307. US: Elsevier Science/JAI Press

Zhang, X., \& Bartol, K. M. (2010). Linking Empowering Leadership and Employee Creativity: The Influence of Psychological Empowerment, Intrinsic Motivation, and Creative Process Engagement. Academy of Management Journal, 53(1), 107-128. doi:10.5465/amj.2010.48037118 


\section{HOW POSITIVE AFFECT LINKS TO PERFORMANCE}


Figure 1. Proposed fully mediated model. Dotted lines show no significant paths.

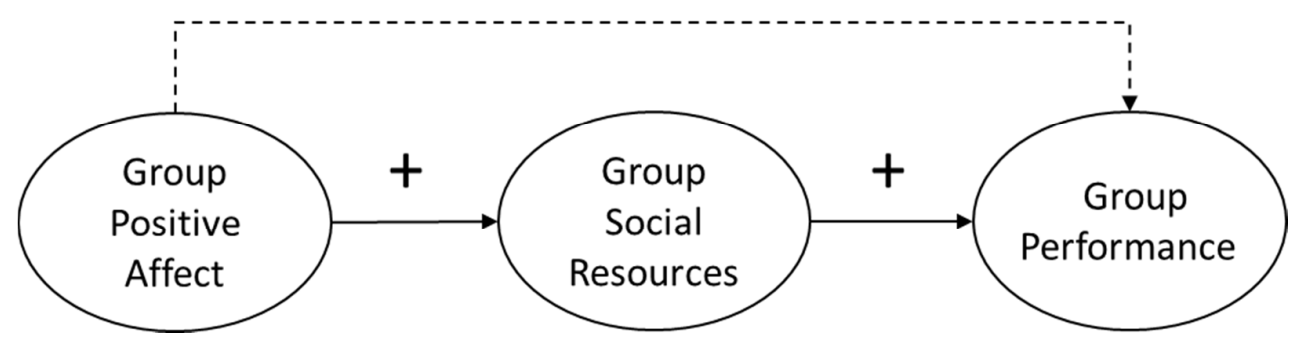

Figure 2. Proposed fully mediated model (Study 1). Dotted lines show no significant paths.

\section{H4}

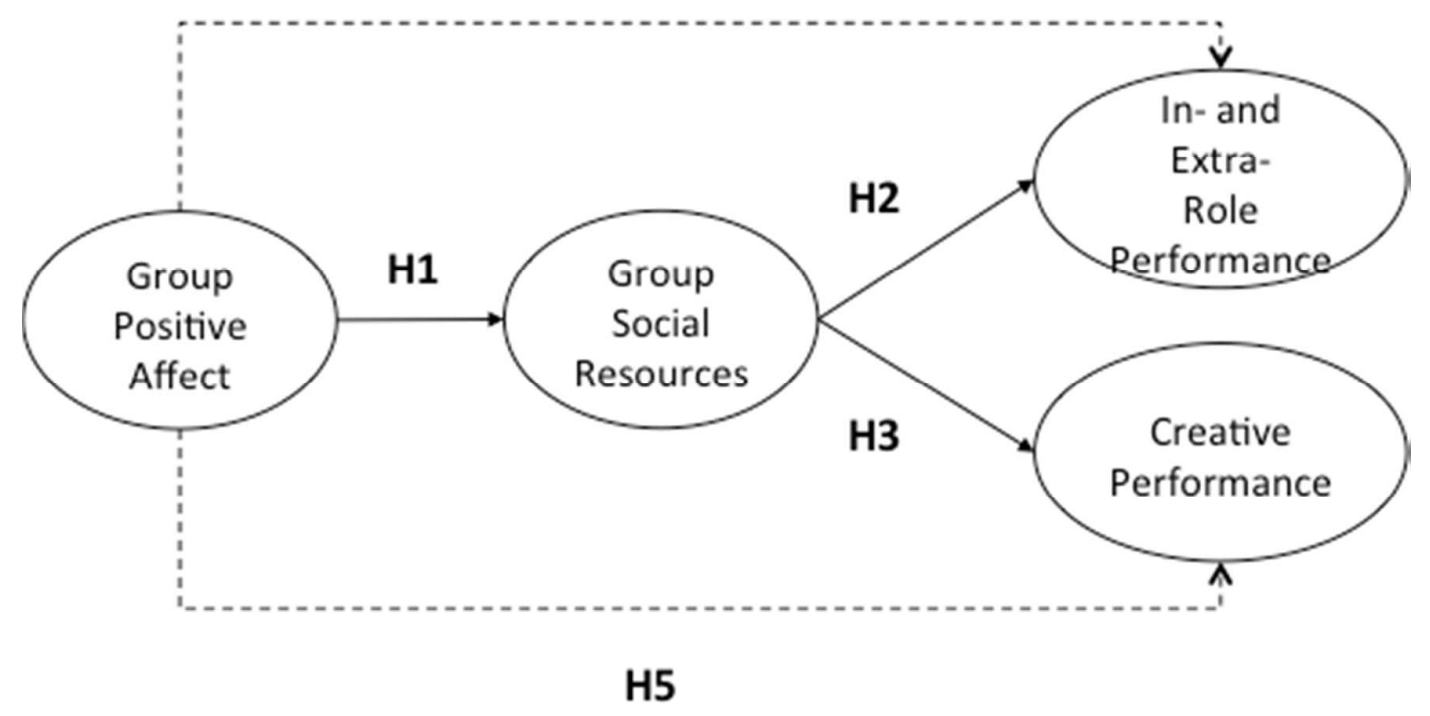

URL: http:/mc.manuscriptcentral.com/rpos Email: journalpospsych@ucdavis.edu 
Figure 3. The final model with standardized path coefficients $(\mathrm{N}=112)($ Study 1$)$

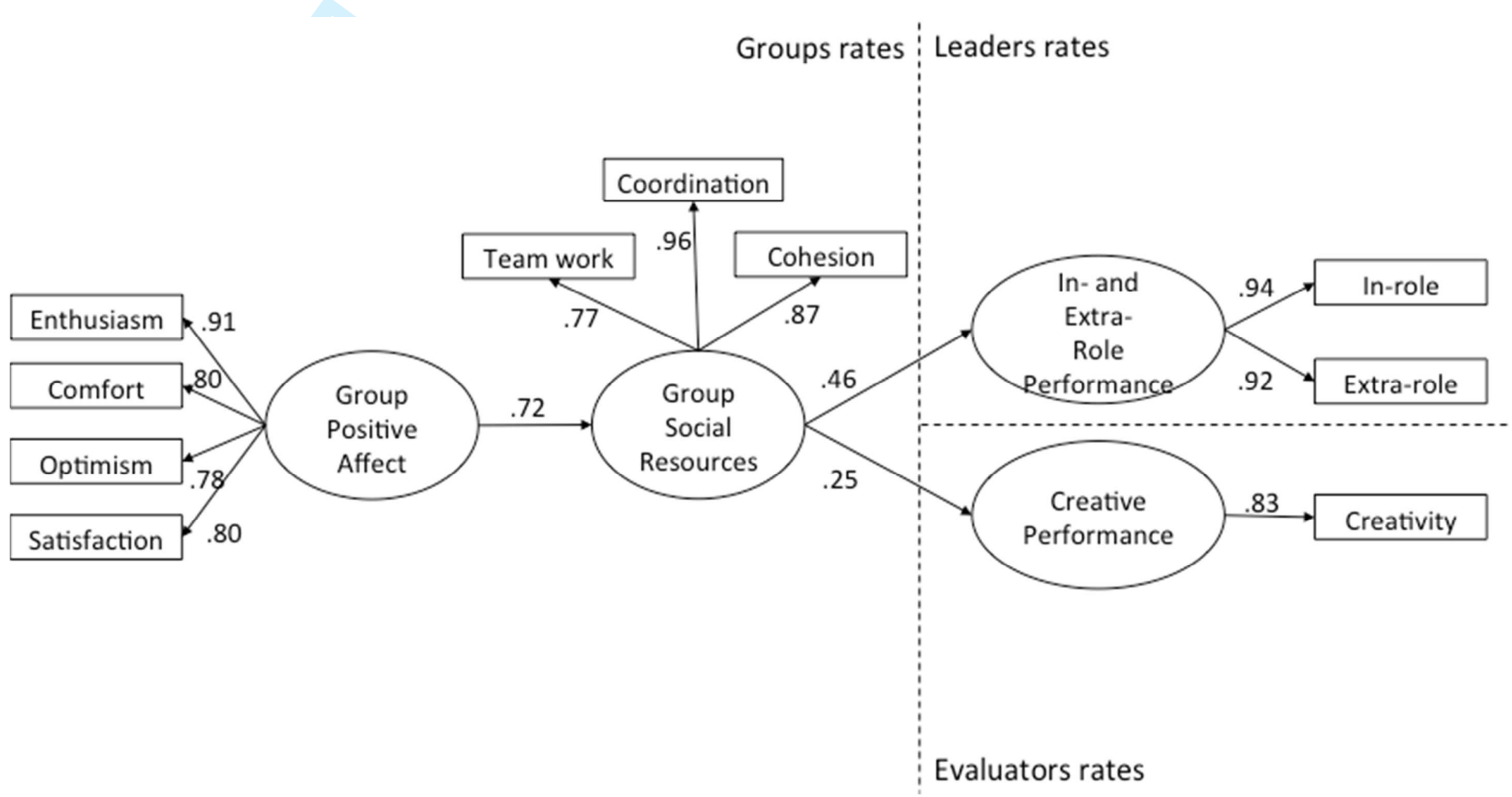

URL: http:/mc.manuscriptcentral.com/rpos Email: journalpospsych@ucdavis.edu 
Figure 4. Proposed fully mediated model. (Study 2). Dotted lines show no significant paths

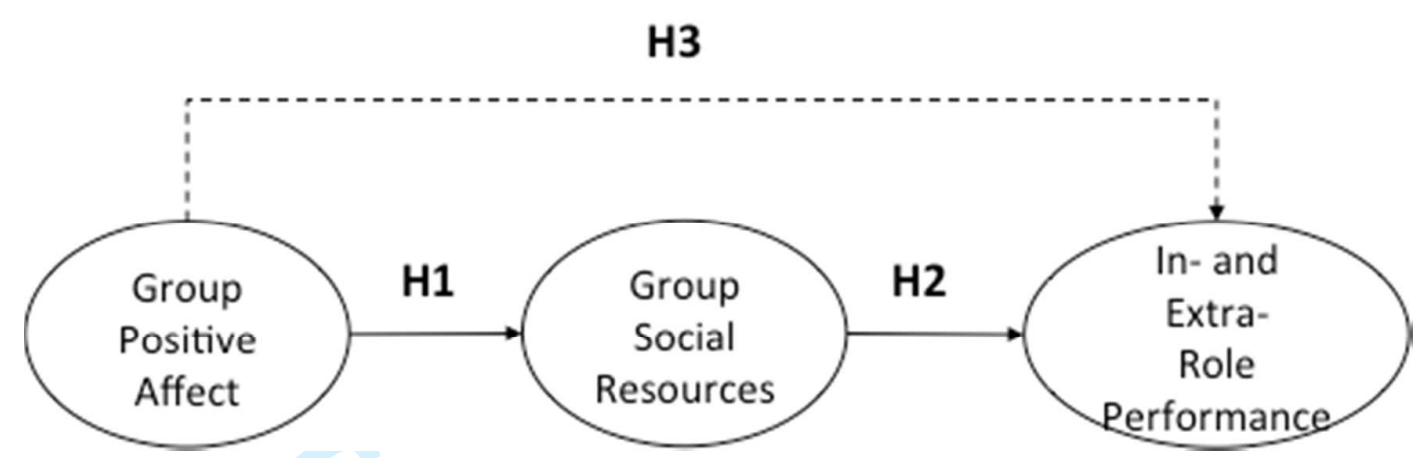

19

20

21

22

23

24

25

26

27

28

29

30

31

32

33

34

35

36

37

38

39

40

41

42

43

44

45

46

47

48

49

50

51

52

53

54

55

56

57

58

59

60

URL: http:/mc.manuscriptcentral.com/rpos Email: journalpospsych@ucdavis.edu 
HOW POSITIVE AFFECT LINKS TO PERFORMANCE

Figure 5. The final model with standardized path coefficients $(\mathrm{N}=417)($ Study 2$)$

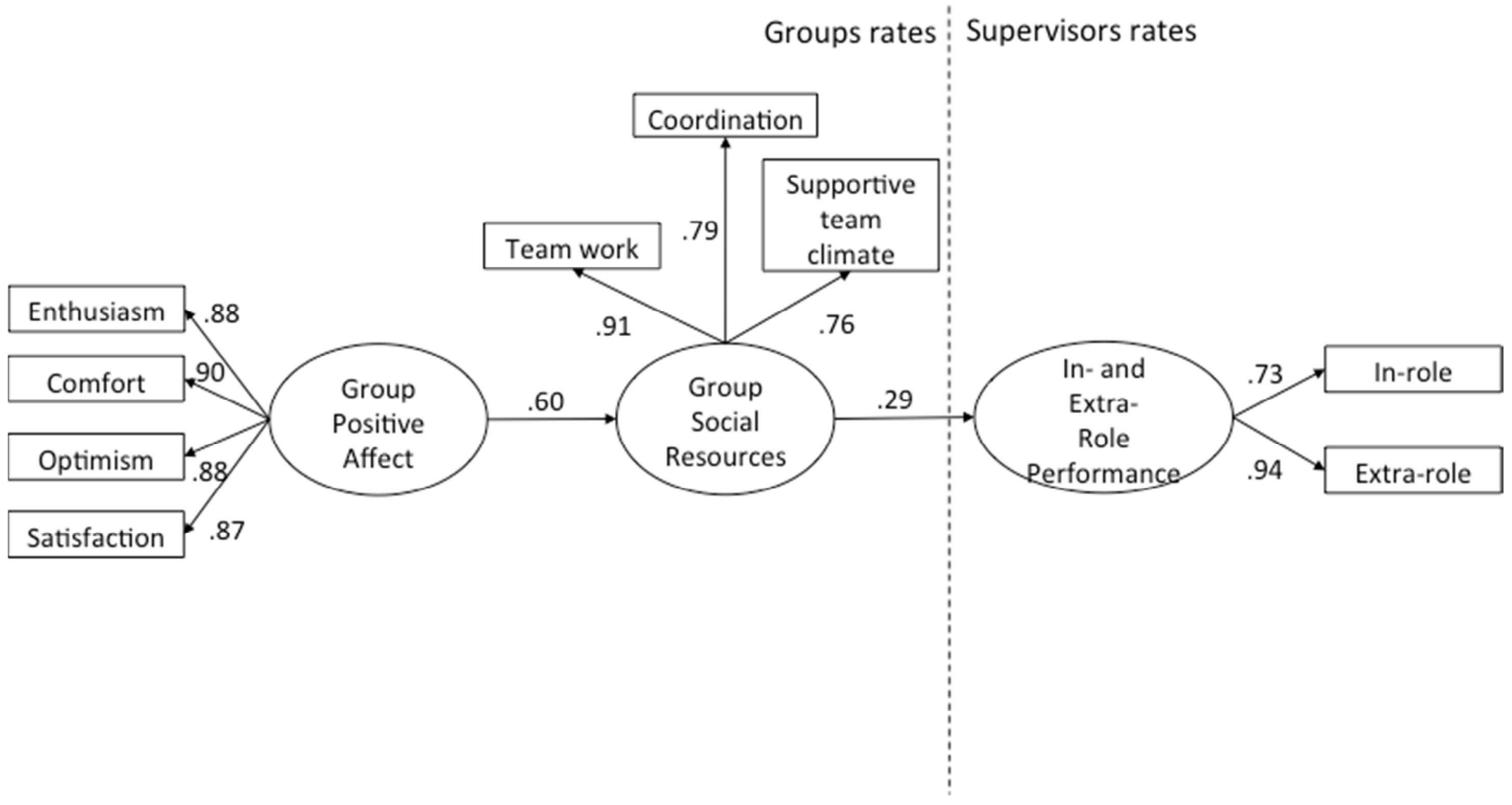


4

5

6

7

8

9

10

11

12

13

14

15

16

17

18

19

20

21

22

23

24

25

26

27

28

29

30

31

32

33

34

35

36

37

38

39

40

41

42

43

44

45

46

47

48

49

50

51

52

53

54

55

56

57

58

59

60

URL: http:/mc.manuscriptcentral.com/rpos Email: journalpospsych@ucdavis.edu 
Table 1

Means, standard deviations, aggregation indices, reliability, and correlations for the study variables (Study 1)

\begin{tabular}{|c|c|c|c|c|c|c|c|c|c|c|c|c|c|c|}
\hline Variables & $\mathrm{M}$ & SD & $\mathrm{AD}_{\mathrm{M}}$ & $\mathrm{ICC}(1)$ & 1 & 2 & 3 & 4 & 5 & 6 & 7 & 8 & 9 & 10 \\
\hline 1. Enthusiasm & 5.17 & .62 & .58 & .15 & - & $.68^{* *}$ & $.75^{* *}$ & $.70^{* *}$ & $.39^{* *}$ & $.45^{* *}$ & $.50^{* *}$ & - & - & - \\
\hline 2. Comfort & 5.33 & .55 & .54 & .10 & $.76^{* *}$ & - & $.65^{* *}$ & $.59^{* *}$ & $.36^{* *}$ & $.44^{* *}$ & $.51^{* *}$ & - & - & - \\
\hline 3. Optimism & 5.17 & .64 & .59 & .14 & $.81^{* *}$ & $.69^{* *}$ & - & $.74^{* *}$ & $.36^{* *}$ & $.45^{* *}$ & $.46^{* *}$ & - & - & - \\
\hline 4. Satisfaction & 5.28 & .65 & .54 & .18 & $.82^{* *}$ & $.68^{* *}$ & $.80^{* *}$ & - & $.34^{* *}$ & $.41^{* *}$ & $.44^{* *}$ & - & - & - \\
\hline 5. Teamwork & 4.66 & .57 & .59 & .25 & $.55^{* *}$ & $.46^{* *}$ & $.52^{* *}$ & $.56^{* *}$ & $(.71)$ & $.67^{* *}$ & $.54^{* *}$ & - & - & - \\
\hline 6. Coordination & 4.82 & .59 & .68 & .23 & $.57^{* *}$ & $.59^{* *}$ & $.57^{* *}$ & $.65^{* *}$ & $.75^{* *}$ & $(.88)$ & $.71^{* *}$ & - & - & - \\
\hline 7. Cohesion & 5.32 & .54 & .53 & .20 & $.58^{* *}$ & $.58^{* *}$ & $.56^{* *}$ & $.66^{* *}$ & $.64^{* *}$ & $.84^{* *}$ & (.94) & - & - & - \\
\hline $\begin{array}{l}\text { 8. In-role } \\
\text { performance } \\
\text { (Leader assessed) }\end{array}$ & 5.03 & .89 & - & - & $.29^{* *}$ & $.23^{*}$ & $.25^{* *}$ & $.32^{* *}$ & $.32^{* *}$ & $.42^{* *}$ & $.34^{* *}$ & $(.92)$ & - & - \\
\hline $\begin{array}{l}\text { 9. Extra-role } \\
\text { performance } \\
\text { (Leader assessed) }\end{array}$ & 4.95 & .91 & - & - & $.28^{* *}$ & $.25^{* *}$ & $.21^{*}$ & $.27^{* *}$ & $.29^{* *}$ & $.41^{* *}$ & $.38^{* *}$ & $.86^{* *}$ & $(.86)$ & - \\
\hline $\begin{array}{l}\text { 10. Creativity } \\
\text { performance } \\
\text { (Evaluators } \\
\text { assessed) }\end{array}$ & 3.28 & .09 & .84 & .46 & $.19^{*}$ & $.22^{*}$ & $.20^{*}$ & $.20^{*}$ & $.19^{*}$ & $.20^{*}$ & .13 & .17 & .11 & - \\
\hline
\end{tabular}

Note: Correlations are presented at the individual-level $(\mathrm{n}=453$, above the diagonal) and at the team-level ( $\mathrm{n}=112$, below the diagonal).

Coefficient alpha reliability estimates are listed in the diagonal in parentheses.

$* \mathrm{p}<.05 ; * * \mathrm{p}<.01$ 
Table 2.

Goodness-of-fit indices for the SEM models (Study 1)

\begin{tabular}{lcccccccccccc}
\hline \multicolumn{1}{c}{ Models } & $\chi^{2}$ & $d f$ & $\mathrm{p}$ & RMSEA & CFI & NFI & TLI & IFI & AIC & $\Delta \chi^{2}$ & $\Delta d f$ & $\Delta$ AIC \\
\hline M1 & 40.87 & 33 & .16 & .05 & .99 & .95 & .987 & .99 & 104.87 & & \\
M2 & 39.61 & 31 & .14 & .05 & .99 & .95 & .985 & .99 & 107.61 & \\
Diff. M1-M2 & & & & & & & & & & $1.24 \mathrm{~ns}$ & 2 \\
M3 & 49.73 & 3 & .03 & .07 & .98 & .94 & .97 & .98 & 113.73 & & \\
Diff. M1-M3 & & & & & & & & & & & \\
\hline
\end{tabular}

Notes: $\chi 2=$ Chi-square; $\mathrm{df}=$ degrees of freedom; RMSEA= Root Mean Square Error of Approximation; NFI= Normed Fit Index; TLI= TuckerLewis Index; IFI= Incremental Fit Index; AIC= Akaike Information Criterion $\mathrm{ns}=$ non-significant 
Table 3

Means, standard deviations, aggregation indices, reliability, and correlations for the study variables (Study 2)

\begin{tabular}{lcccccccccccccc}
\hline \multicolumn{1}{c}{ Variables } & $\mathrm{M}$ & $\mathrm{SD}$ & $\mathrm{AD}_{\mathrm{M}}$ & $\mathrm{ICC}(1)$ & 1 & 2 & 3 & 4 & 5 & 6 & 7 & 8 & 9 \\
\hline 1. Enthusiasm & 3.64 & 1.04 & .93 & .16 & - & $.73^{* *}$ & $.69^{* *}$ & $.68^{* *}$ & $.36^{* *}$ & $.30^{* *}$ & $.35^{* *}$ & - & - \\
2. Comfort & 4.17 & 1.03 & .92 & .13 & $.79^{* *}$ & - & $.69^{* *}$ & $.72^{* *}$ & $.38^{* *}$ & $.32^{* *}$ & $.35^{* *}$ & - & - \\
3. Optimism & 4.02 & 1.02 & .94 & .13 & $.79^{* *}$ & $.78^{* *}$ & - & $.70^{* *}$ & $.35^{* *}$ & $.29^{* *}$ & $.31^{* *}$ & - & - \\
4. Satisfaction & 4 & 1.09 & .94 & .15 & $.74^{* *}$ & $.79^{* *}$ & $.78^{* *}$ & - & $.35^{* *}$ & $.30^{* *}$ & $.34^{* *}$ & - & - \\
5. Team work & 4.84 & .76 & .87 & .18 & $.47^{* *}$ & $.51^{* *}$ & $.42^{* *}$ & $.50^{* *}$ & $. .80)$ & $.67^{* *}$ & $.55^{* *}$ & - & - \\
$\begin{array}{l}\text { 6. Coordination } \\
\text { 7. Supportive team }\end{array}$ & 4.66 & .76 & .88 & .15 & $.40^{* *}$ & $.45^{* *}$ & $.39^{* *}$ & $.37^{* *}$ & $.74^{* *}$ & $(.82)$ & $.47^{* *}$ & - & - \\
$\begin{array}{l}\text { climate } \\
\text { p. In-role }\end{array}$ & 3.81 & 1.1 & 1.2 & .23 & $.48^{* *}$ & $.54^{* *}$ & $.44^{* *}$ & $.45^{* *}$ & $.69^{* *}$ & $.57^{* *}$ & $(.84)$ & - & - \\
$\begin{array}{l}\text { 9. Extra-role } \\
\text { performance }\end{array}$ & 4.68 & .87 & - & - & $.13^{* *}$ & $.16^{* *}$ & $.11^{*}$ & $.15^{* *}$ & $.19^{* *}$ & $.15^{* *}$ & $.19^{* *}$ & $(.86)$ & - \\
\hline
\end{tabular}

Note: Correlations are presented at the individual-level $(n=2,159$, above the diagonal) and at the team-level ( $\mathrm{n}=417$, below the diagonal). Coefficient alpha reliability estimates are listed in the diagonal in parentheses.

$* \mathrm{p}<.05 ; * * \mathrm{p}<.01$ 
Table 4.

Goodness-of-fit indices for the SEM models (Study 2)

\begin{tabular}{|c|c|c|c|c|c|c|c|c|c|c|c|c|}
\hline Models & $\chi^{2}$ & $d f$ & $\mathrm{p}$ & $\begin{array}{c}\text { RMSE } \\
\text { A }\end{array}$ & CFI & $\begin{array}{c}\mathrm{NF} \\
\mathrm{I}\end{array}$ & TLI & IFI & AIC & $\Delta \chi^{2}$ & $\begin{array}{c}\Delta d \\
f\end{array}$ & $\Delta \mathrm{AIC}$ \\
\hline M1 & 62.45 & 25 & .00 & .06 & .99 & .98 & .99 & .99 & 120.45 & & & \\
\hline M2 & 62.44 & 24 & .00 & .06 & .98 & .98 & .98 & .98 & 122.44 & & & \\
\hline $\begin{array}{l}\text { Diff. } \\
\text { M1-M2 }\end{array}$ & & & & & & & & & & $\begin{array}{l}.01 \\
\text { ns }\end{array}$ & 1 & 2.28 \\
\hline $\begin{array}{l}\text { M3 } \\
\text { Diff. }\end{array}$ & 78.916 & 25 & .00 & .07 & .98 & .97 & .97 & .99 & 136.92 & & & \\
\hline M1-M3 & & & & & & & & & & & & 16.46 \\
\hline
\end{tabular}

Notes: $\chi 2=$ Chi-square; $\mathrm{df}=$ degrees of freedom; RMSEA= Root Mean Square Error of Approximation; NFI= Normed Fit Index; TLI= Tucker-Lewis Index; IFI= Incremental Fit Index; AIC $=$ Akaike Information Criterion ns $=$ non-significant 